\title{
Research on Archive Security Work in China's Colleges and Universities based on Information Disclosure System
}

\author{
Xiaohui Dai \\ Taishan University, Tai'an, 271021, China
}

Keywords: Information disclosure system, China's universities and colleges, Archive security work

\begin{abstract}
As archives management is a systematic project, including the contents of the file finishing and archiving, etc.; meanwhile, the university archives contain personal data and privacy of students and teaching as well as scientific research, so archive security is very necessary. In the process of archives management, the universities must strengthen the archives security work to ensure the protection of rights of students and schools are maintained, and ensure the confidentiality of their personal information. In addition, the information disclosure system not only plays the role of homologous symbiosis, but also has a contradiction confidential relationship with archives security. Thus, this paper conducted research on university archives security work based on information disclosure system, performed analysis for the relation between information disclosure system and university archives security work, and put forward the specific measures for university archive security work under reinforcement of information disclosure system, thus providing a strong guarantee for the protection of information of colleges and universities.
\end{abstract}

\section{Introduction}

Currently, in the case of continuous reform and deepening of the educational system, the university has increased the intensity of information disclosure, and then for the good development of education has laid a good foundation. Of course, the university archives in carrying out secret work, still there are many problems, leading to archive information has not been effectively protected. For example, the current information disclosure of the existence of the relevant laws and great contradictions, there is a certain contradiction University Archives confidentiality and information disclosure system, and cause the university archives confidentiality failed to achieve good results. Therefore, universities must increase research on information disclosure, through the establishment of a sound records management mechanism, then there is conducive to confidentiality of University Archives. Of course, the university archives in carrying out secret work, still there is a contradiction between the information disclosed, and then lead records management lags behind. For managing the university by law, colleges and universities must complete sound archive management mechanism in the same time, efforts to increase information disclosure, so as to enhance the level of file management, file security work to promote the construction of universities, colleges and universities must improve all aspects of records management, and then for the secret archives working to provide a favorable protection.

\section{The significance of China's universities to conduct archive security work}

With the deepening of the educational system, the university in the development process of the archives must be reasonable development and utilization, and then provide a favorable protection to carry out security work university archives, so as to achieve the effect of law school.

Currently, to carry out information disclosure is to enhance the university archives confidential work must, in order to seriously implement the scientific concept of development, for students to create a harmonious campus environment, universities must enhance the transparency of the work. Archives confidentiality of records management as an essential element, is also an important part of archives management. Because colleges and universities in the file management process, need to be prepared for the archives of the different periods of teaching, research, student information, etc., so 
that the results of university history to be preserved, then these data provide evidence for a favorable future work. Of course, the management of files at the same time, we must intensify archives confidential work. In addition, in order to ensure file authenticity information, so colleges and universities to increase the intensity of the public process, we must focus on education to ensure confidentiality of the work of the various departments so that the university archives confidential work to achieve good results.

\section{The relation between information disclosure system and China's college archive security}

In the democratic political construction process, universities need to work in accordance with the relevant provisions of the information disclosure system, making the information public universities to be safeguarded. Education sector "University Information Disclosure Rules", which clearly stated that the information disclosed in an effective way and with the relevant requirements [1]. Meanwhile, the university information disclosure has also been standardized. Universities in carrying out information disclosure process, by means of information open bar, multimedia campus sites, open to the whole school-related information, and an open mind to listen to the views and suggestions of teachers and students, and then under the joint supervision of teachers and students to ensure that students and teachers get certain right to know. Currently, information disclosure contains infrastructure tender, student cadres' appointment and job classification, housing distribution, etc., which are related to the construction of university teachers and students and the vital interests of the closely related, so the information is disclosed for the development of colleges and universities have provided favorable conditions. At the same time, but also to build a harmonious campus and safeguard the vital interests of teachers and students to provide a guarantee. Since the information is disclosed, strengthening the democratic management and supervision of universities, but also to enhance the transparency of the main conditions. Meanwhile, the university archives Confidentiality is an important part of file management, file management and therefore in order to improve the quality of information disclosure must be reasonable, thus making the management of the new university archives to achieve good results. University archives described the student work, teaching and research, and campus construction, etc., the file contains all the development achievements of colleges and universities, so the archives confidentiality is extremely important. In addition, the "Archives Act" that universities and other units should sound and rational management system, and set the related facilities, so as to enhance the security of archives. Therefore, information disclosure and confidentiality university archives homologous contact with students, and college archives management information disclosure is an important part of university archives in carrying out secret work, sure to be a reasonable use of information disclosure, and then reflect the objective situation Universities.

\section{Contradiction of college archive security work produced based on information disclosure system}

Although the information disclosure and university archives homologous contact with students, but there are contradictions between the two phase nature, and then limit the conduct of university archives confidential work. History Archives is the state organs and social organizations engaged in various activities in the course of direct or indirectly, and these records are valuable. For the university archives confidential work, in order to promote the work carried out, the relevant personnel must be divided from the perspective of confidentiality. Currently, from the perspective of confidentiality, university archives in total divided into two categories, namely, classified and non-classified archives. For the secret archives, from the narrow sense, refers to the period of time, the file has to be a certain level of archiving and preservation, and then in favor of universities for teaching, research, government and other content to be to create the file, and these files be treated confidentially. Since the files contain personal privacy and commercial secrets, so the state has adopted a series of laws to regulate the work of the secret archives. For example, the "Archives Act 
for People's Republic of China" on the secrecy of the archives put forward specific requirements, clearly stated in the university archives cannot be made public the following information: related to trade secrets and state secrets are not public, and withheld information about individuals . Furthermore, national laws, regulations, and rules and regulations and other information related to colleges and universities will not be made public. Meanwhile, in order to vigorously promote the development of information disclosure, and must ensure that the public and the majority of teachers and students to obtain college information process must be carried out according to the law, and to improve transparency in the University. Universities should also get good results by strengthening the management and supervision of the people, thus vigorously promoting democratic governance of the school and in University law school.

Colleges and universities to carry out secret archives work, information disclosure must be reasonable and must ensure public and university teachers and students have the right to know and the right to participate and to supervise. Meanwhile, the full use of universities Home, route specific information public website and campus electronic screens, strengthen information disclosure transparency, so that the effectiveness of information has, generally speaking, to carry out when the information disclosed by the use of these instruments must have a wide range of media transparency ${ }^{[2]}$. However, the presence of these properties, but also determines a certain contradiction between information disclosure and confidentiality university archives, in particular the performance of universities contradiction must functioning CRDA, and then do the file management and security work. In addition, information disclosure and provide valuable information to maximize resources for college students and the general public. In short, information disclosure and university archive security have contradiction with nature.

\section{Measures to reinforce college archive security work under information disclosure system}

\section{Insist appropriateness principle to conduct archive security work}

With the continuous deepening of reform of the education system and the educational form has undergone tremendous change, requires colleges and universities in the development process must strengthen the management of archives, and then adapt to the basic requirements of education. Universities in the construction process, file management must have sufficient knowledge, by taking a series of measures to improve records management level, thus providing a favorable basis for the further development of universities. Universities will build archives for teaching, research, awarding in different periods, and then provide the conditions for universities to carry out future research, teaching, students and other work. However, the file contains important information resource and personal privacy, so as the university archives in carrying out secret work put forward higher requirements. Thus, a university enhances the quality of archive security work under information disclosure system.

Because information disclosure and college archive security work has a certain contradiction, over time, lead to university archives management is difficult to guarantee the quality of work, especially in carrying out secret archives work, too much emphasis on secrecy, while ignoring the public. At the same time, will continue to exist over an open, resulting in decreased strength confidential file, so open to work with universities to balance the information confidential archives, universities must adhere to the principle of moderation, earnestly implement the "University Information Disclosure Rules" to enhance transparency and universities, and by universities democratic management, speed up the process of law school ${ }^{[3]}$. In addition, in strict accordance with the basic requirements of the party group promoting education university information disclosure work, in order to actively carry out information disclosure, universities must establish a sound organizational information disclosure, information disclosure to increase efforts to train and deepen the reform of information and the disclosure of such universities maintain students and participation rights, the right to know and supervise the public to provide a favorable protection.

In addition, colleges and universities in the process of information disclosure process, we must adhere to the principle of moderation, archives confidential information to be kept confidential, the 
timely release of public information, in order to truly enhance information disclosure transparency. This will not only ensure the confidentiality archives achieved good results, and improve service quality. In short, only colleges and universities in order to promote the sound development of various undertakings, must accurately grasp the relationship between information disclosure system and college archive security in improving security while archives, correctly handle the information disclosure, so as to lay a good foundation for the development of universities.

\section{Reasonably use time difference relation}

In order to ensure the confidentiality of University Archives quality, improve file management, and coordination of information disclosure and confidentiality of the relationship between archives, through rational use of the time difference, so to correctly handle archives confidentiality, but also so that the information disclosed in the scientific status. Universities in carrying out the activities of daily activities must correctly handle the information disclosure work, publishing a variety of information through the use of modern methods, thereby ensuring information disclosure limit its disclosure mutual adaptation, and to carry out various forms by regular and irregular manner so that information disclosure and confidentiality University Archives adapt. "University Information Disclosure Rules" for information disclosure, there are strict requirements for active public information day, college or obtain the information necessary to complete the production of 20 working days from, for information to be disclosed, if the disclosure of information contents have changed [3], the contents of 20 working days from the date of update must change it. Currently, the university archives generally refers to non-confidential information has value, but still able to reflect the real activity Universities and valuable content, in order to enhance openness and work organization, must be long-term, periodic, temporary work were to be Regular, paragraph by paragraph, at any public, for the complexity of the issue, public opinion must be combined with feedback to improve them, if necessary, the need to implement public again. Under normal circumstances, the time is not less than a week the formula [4]. Meanwhile, in order to strengthen the management of archives, you must be within a certain period of time it is open to the public, and in the actual work process, archives between various departments of universities need to transfer to the archives in the second year. Universities can make full use of the time difference; correctly handle the information disclosure and confidentiality archives.

\section{Establish complete college security work system}

Colleges and universities in order to enhance the quality of work in the archives confidential information disclosed under the guidance system, through the establishment of a sound system of university archives confidentiality, thereby to improve the file management level to provide a strong guarantee. Schools of activities carried out in the process, need to be teaching, research and other content to be recorded, then the processing of information to be archived, so the great importance of information in the archives. Colleges and universities to carry out secret archives work, must continue to improve the work of university archives secrecy system to ensure that archives staff to follow the norms of discipline strictly confidential and confidential work vigorously University Archives. University archives perfect secrecy system should file finishing, storage, etc. to be standardized, and contains access to archives, access to other content related procedures. Universities should also be combined with "Secrets Act" to develop and archives related to the confidentiality rules, making the system more complete archives secrecy [5]. Meanwhile, the system should cover leadership and approval system but the system file destruction, thereby ensuring a favorable basis for the development work of the university archives confidentiality.

\section{Conclusions}

During the process of universities development, we must strengthen the management of archives, so as to provide a favorable protection for research, teaching and students' work. Archive security work as the main content of archive management, plays a key role to enhance the security of archives. Currently, the information disclosure system is an important part of college democratic political construction which also brings hope for the development of college archive security work. It also led 
to university archives confidentiality facing severe challenges. Therefore, the universities must take effective measures to coordinate the relationship between the two, so as to enhance the confidentiality of university archives.

\section{References}

[1] Zhao Rong. Discussion and analysis on archive security management work under college information disclosure system. Education Observation, 2013(5):59-60,67.

[2] Fan Lei. Problems of archive management existed in the environment of college information disclosure and countermeasures. China Science and Technology Information, 2012(22):148.

[3] Liu Jiawei. Analysis on university archive security work. Journal of Qiqihar Medical University, 2015(23):3549-3549.

[4] Ding Xunhua. Archive management research in context of university information disclosure. Examination Weekly, 2014(83):150-151.

[5] Wang Fang. Analysis on archive security work under environment of information disclosure.SME management and technology, 2013(25):152-153. 